\title{
Stress-Related Brain Neuroinflammation Impact in Depression: Role of the Corticotropin- Releasing Hormone System and P2X7 Receptor
}

\author{
Susana Silberstein ${ }^{a}$ Ana Clara Liberman ${ }^{a}$ Paula Ayelén dos Santos Claro ${ }^{a}$ \\ Maria Belén Ugo ${ }^{a}$ Jan M. Deussing ${ }^{b}$ Eduardo Arzt ${ }^{a, c}$ \\ anstituto de Investigación en Biomedicina de Buenos Aires (IBioBA)-CONICET-Partner Institute of the \\ Max Planck Society, Buenos Aires, Argentina; ${ }^{b}$ Max Planck Institute of Psychiatry, Munich, Germany; \\ 'DFBMC, Facultad de Ciencias Exactas y Naturales, Universidad de Buenos Aires, Buenos Aires, Argentina
}

\section{Keywords}

Neuroinflammation $\cdot \mathrm{P} 2 \mathrm{X} 7$ receptor .

Corticotropin-releasing hormone receptor signaling .

Corticotropin-releasing hormone system

pathophysiology · Stress · Depression

\section{Abstract}

Depression and other psychiatric stress-related disorders are leading causes of disability worldwide. Up to date, treatments of mood disorders have limited success, most likely due to the multifactorial etiology of these conditions. Alterations in inflammatory processes have been identified as possible pathophysiological mechanisms in psychiatric conditions. Here, we review the main features of 2 systems involved in the control of these inflammatory pathways: the $\mathrm{CRH}$ system as a key regulator of the stress response and the ATP-gated ion-channel P2X7 receptor (P2X7R) involved in the control of immune functions. The pathophysiology of depression as a stress-related psychiatric disorder is depicted in terms of the impact of CRH and P2X7R function on inflammatory pathways in the brain. Understanding pathogenesis of affective disorders will lead to the development of therapies for treatment of depression and other stressrelated diseases.

(c) 2021 S. Karger AG, Basel

\section{Introduction}

Stress exposure is considered the main environmental trigger of psychiatric disorders, such as depression. Depression is a significant contributor to the global burden of disease, affecting people in all communities across the world. This condition is estimated to affect more than 350 million people worldwide, resulting in a significant public health challenge, not only at the clinical level but at the social and economic levels as well. Over the years, there has been a significant amount of research on depression. Currently, latest evidence on the link between depression and inflammation mechanisms is opening new avenues for investigating stress pathophysiology and identifying therapeutic targets for stress-related disorders.

The neuropeptide corticotropin-releasing hormone $(\mathrm{CRH})$, also named corticotropin-releasing factor, plays a crucial role in the integration of neuroendocrine, autonomic, and behavioral responses to stress [1]. Hypothalamic $\mathrm{CRH}$-secreting neurons are essential to the stress response driving both basal and stress-induced hypothalamic-pituitary-adrenal (HPA) axis activation. CRH is also widely distributed in extrahypothalamic circuits of the brain where it acts as a neuromodulator to establish and integrate a complex humoral and behavioral system karger@karger.com

(c) 2021 S. Karger AG, Basel

www.karger.com/nim

Karger ${ }^{\prime \prime}=$
Correspondence to:

Eduardo Arzt, earzt@ibioba-mpsp-conicet.gov.ar 


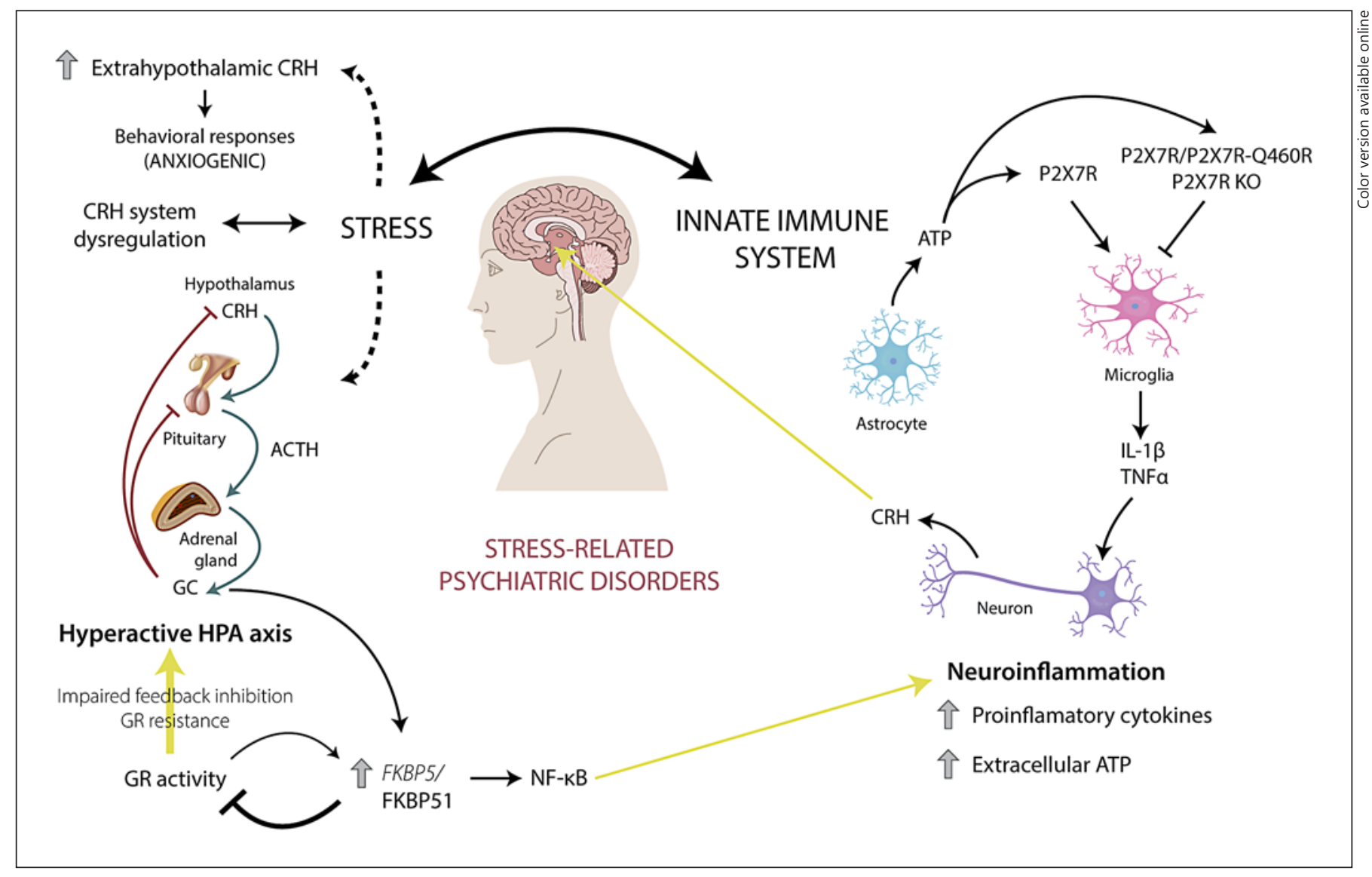

Fig. 1. Schematic representation of the bidirectional relationship between stress and the innate immune system in the context of stress-related psychiatric disorders. Stress is tightly related to $\mathrm{CRH}$ system dysregulation. Chronic stress exposure may lead to an increase in extrahypothalamic CRH and HPA axis hyperactivity possibly due to GR resistance. GR activity can be modulated among others, by the Hsp90 co-chaperone FKBP51 which is a negative regulator of GR activity. FKBP51 function can be modulated at the gene level due to genetic variants, epigenetic modifications, and environmental stressors, or at the protein level via PTMs. Increased FKBP51 expression/function is related to GR hyposensitivity. Together with GC, FKBP51 regulates inflammation by regu- lating the master proinflammatory transcription factor NF- $\kappa \mathrm{B}$. In turn, stress increases the release of ATP from astrocytes, which binds to microglial P2X7R and activates the innate immune system, resulting in the synthesis and release of proinflammatory cytokines such as IL-1 $\beta$. P2X7-Q460R variant is often found in mood disorder patients and its coexpression with WT P2X7R dramatically impairs receptor activity. IL- $1 \beta$ may induce the secretion of hypothalamic $\mathrm{CRH}$ contributing to HPA hyperactivity. $\mathrm{CRH}$, corticotropin-releasing hormone; FKBP5, gene encoding FKBP51; HPA, hypothalamic-pituitary-adrenal; GCs, glucocorticoids; PTMs, posttranslational modifications; P2X7R, P2X7 receptor. that regulates multiple aspects of the stress response [1, 2]. $\mathrm{CRH}$ system dysregulation is critically involved in stress-related disorders: psychiatric conditions (depression, anxiety, and addiction), and neuroendocrinological alterations and has been found to impact on the onset and development of neurodegenerative processes $[3,4]$. The bidirectional relationship between stress and the immune system has long been evidenced (Fig. 1): several neuropsychiatric disorders can be promoted by inflammation, and the brain can also exert control over the immune response [5].
Besides neurobiological results, stress exposure impacts on the innate immune system, leading to increased production and secretion of proinflammatory cytokines by the sensing of extracellular signals by microglia, the brainresident macrophages. The increase of extracellular ATP is sensed by the P2X7 receptor (P2X7R), activating the inflammasome cascade that leads to the release of IL-1 16 [6. Thus, P2X7R is a key player in the neuroinflammatory pathways, leading to the onset and progression of a broad range of psychiatric disorders [7]. Notably, a genetic association between the P2RX7 gene and mood disorders and

Neuroimmunomodulation 2021;28:52-60 
its interaction with stressful environmental factors points to P2X7R as a promising target for development of novel therapeutics for neuropsychiatric diseases [8].

We review the main characteristics of CRH and P2X7R in terms of the crucial role of stress and neuroimmune responses in the pathogenesis of depression. Studying the interaction of stress and immune responses can enhance our understanding of the pathogenesis of depression and will impact on development of therapies for stress-related psychiatric disorders.

\section{The HPA Axis and Extrahypothalamic CRH on the Onset of the Stress Response and Stress-Related Disorders}

Glucocorticoids (GCs), the main product of HPA axis activity, are important regulators of various physiological processes such as metabolism, behavior, and immune function. The role of GCs in restraining the inflammatory response has been well established [9-11]. As a negative feedback mechanism, GCs bind to hypothalamic and pituitary glucocorticoid receptors, which leads to the inhibition of ACTH and CRH restoring GC levels. This negative feedback is fundamental for the termination of the HPA axis response to stress and for optimal secretion of GCs. Hyperactivity of the HPA axis and GR dysfunction are among the most consistent biological findings in depressed patients $[1,12,13]$. Depression is highly prevalent in infectious and autoimmune diseases, and at the same time, depressed patients show an enhanced inflammatory state that contributes to the behavioral changes [14]. Therefore, HPA axis hyperactivity and inflammation (Fig. 1), both ascribed to an impairment of GR activity, are thought to be part of the same pathophysiological process [15]. Multiple mechanisms such as epigenetics marks, increased expression of GR $\beta$ isoform, microRNAs, posttranslational modifications and the expression of Hsp90 co-chaperone FKBP51 might be involved in the changes in GR feedback sensitivity [15]. FKBP51 decreases GR ligand-binding affinity and nuclear translocation-inhibiting GR-mediated regulation of gene expression. The discovery that FKBP51 inhibits GR led to the hypothesis that increased expression of FKBP51 may be associated with HPA axis hyperactivity and to psychiatric disorders. Variations in the function of this chaperone can be caused by the loss of inhibition of FKBP5 - the gene encoding the FKBP51 protein - due to genetic variants, epigenetic modifications, and environmental stressors. Increased levels of FKBP5 have been shown to contribute to psychiatric conditions $[16,17]$. Interestingly, FKBP5 expression raises in response to elevated cortisol levels, forming an ultra-short negative feedback loop for the regulation of GR activity [18]. Posttranslational modifications of FKBP51 have a strong impact in its function [1921]. Accordingly, alterations of HPA axis reactivity and feedback regulation were observed in FKBP51 KO mice [22]. In addition to the role of GCs in regulating the immune response, FKBP51 has also been implicated in the regulation of inflammation via the regulation of GR and the master proinflammatory transcription factor NF- $\kappa \mathrm{B}$ $[23,24]$. Aging and stress synergize to epigenetically upregulate FKBP51 expression, promoting NFKB-mediated inflammation [25]. This mechanism could account for GR resistance and may contribute to the increase in inflammation described in stressed and aged patients [25].

Besides increasing ACTH release and consequent GC secretion, icv CRH administration leads to anxiety-like behavioral and autonomic effects in rodents [26, 27]. However, anxiety-related outcomes persisted in hypophysectomized rats indicating that behavioral aspects of the response are independent of endocrine HPA axis [28].

Overexpression of $\mathrm{CRH}$ induces an anxiogenic-like phenotype [29], whereas suppressing $\mathrm{CRH}$ expression has anxiolytic effects in both basal and stress-induced anxiety [30]. Genetic and pharmacological studies have linked anxiogenic effects of $\mathrm{CRH}$ to the activation of CRHR1 [31]. In terms of abundance and distribution, CRHR1 is the main CRH receptor in the brain, whereas CRHR2 expression is more restricted [32]. Opposite findings of effects of CRHR subtype activation are observed within discrete brain regions, implicating a highly complex mechanism dependent on region, circuit specificity, cell type, and ligand involved [32].

$\mathrm{CRH}$ and its related peptides act as neuroregulators: they activate cell signaling processes that enhance or depress neurotransmitter effect within specific neuronal circuits without affecting synaptic efficacy or strength [33]. Mice lacking CRHR1 in glutamatergic neurons show reduced anxiety and impaired neurotransmission in the hippocampus and basolateral amygdala. In contrast, mice lacking CRHR1 in dopaminergic neurons or $\mathrm{CRH}$ in neurons innervating midbrain dopaminergic nuclei show increased anxiety-like behavior and reduced dopamine release in the prefrontal cortex $[34,35]$. This differential role for CRHR1 suggests that under physiological conditions, CRHR1-controlled glutamatergic and dopaminergic systems might function in an antagonistic manner to maintain adaptive responses to stressful situations in balance.
Neuroimmunomodulation 2021;28:52-60 DOI: $10.1159 / 000515130$
Silberstein/Liberman/dos Santos Claro/ Ugo/Deussing/Arzt 
Results from clinical studies also support that stressinduced CRH actions are mediated mainly through CRHR1 activation [12]. Studies in humans revealed that epigenetic variations in the CRH system may be predictors of vulnerability to psychiatric stress-related disorders [36]. Collectively, this evidence reinforces the idea of a critical role of the $\mathrm{CRH}$ system in stress-related disorders and highlights the need of a clear definition of molecular components and mechanisms involved in $\mathrm{CRH}$ function for designing new therapies.

\section{The Family of CRH Peptides and Receptors}

The CRH system includes the 41 -amino acid peptide $\mathrm{CRH}$ and in mammals, CRH-related urocortin 1, urocortin 2, and urocortin 3 peptide neurohormones (reviewed in [37]), that are found in both the central nervous system and peripheral tissues with differential patterns of distribution [38]. CRH and the UCNs operate through 2 receptors, CRHR1 and CRHR2, which belong to the class B family of GPCRs. CRHR1 and CRHR2 are encoded by different genes but present a $70 \%$ identity at the amino acid level, with the major divergence found in their amino-terminal domains responsible for their agonist selectivity [37]. The expression of CRH receptors (CRHRs), $\mathrm{CRH}$, and UCNs in different brain regions have been reviewed recently [32].

$\mathrm{CRH}$ and UCNs can signal through various intracellular pathways that depend on cellular context $[37,38]$. Ligand-activated CRHRs are mainly coupled to Gas, resulting in adenylyl cyclase (AC) activation [39-43]. The second messenger cAMP, in turn, activates multiple effectors, being the best characterized the ERK1/2 MAPK cascade [38]. ERK $1 / 2$ is widely distributed in the brain and is a central mediator of molecular processes involved in learning, memory, neuronal plasticity, and response to stress [44].

In the corticotroph-derived cell line AtT20, the cAMPdependent activation of ERK1/2 was critical for the expression of the ACTH precursor POMC $[39,45]$. In addition, the in vivo icv administration of CRH activated ERK1/2 in specific brain structures involved in environmental information processing and behavioral aspects of the stress response, such as hippocampus and basolateral amygdala [46]. The molecular mechanisms underlying ERK1/2 activation in a hippocampal neuronal context have been investigated in mouse hippocampal neuronal HT22 cells as a cellular model (HT22-CRHR1). The temporal profile of ERK1/2 phosphorylation in response to CRH was biphasic, with a first peak 3-6 min after stimulation and a second phase that remained activated for at least $60 \mathrm{~min}$ after $\mathrm{CRH}$ addition [41]. Two different mechanisms mediate ERK1/2 activation, $1 \mathrm{G}$ protein dependent, and a second that required CRHR1 internalization and $\beta$-arrestin2 [41]. Importantly, ERK1/2 activation was dependent on cAMP levels in response to CRH [41, 42]. Using a FRET-based cAMP biosensor, the CRH-elicited cAMP response in different physiologically relevant scenarios [47] revealed that in AtT20 cells, CRH led to a transient increase in cAMP levels [42], but the cAMP response elicited by CRH in hippocampal and cortical primary cell cultures was sustained [43]. Interestingly, both classical transmembrane and atypical soluble ACs (sAC) are involved in both neuronal hippocampal HT22-CRHR1 and AtT20 cells [42]. Moreover, different cAMP sources were found to be involved in different signaling mechanisms: transmembrane AC and sAC were required for acute ERK1/2 activation, but only sAC was critical for sustained phospho-ERK1/2 [41, 42] or CRH-mediated neuritogenic growth in HT22-CRHR1 cells [43]. Therefore, at least in the case of CRHR1, the spatial resolution of the signals is achieved by the involvement of an alternative source of cAMP and not just by the formation of signaling complexes along the endocytic pathway, as in the emerging model of GPCR function which involves sustained signaling from intracellular compartments [37]. The nature of the endocytic compartments that activated CRHR1 transits once internalized, awaits to be determined in neuroendocrine and hippocampal neuronal contexts to define the mechanisms of both acute and sustained CRH signaling.

On the other hand, the mechanism of CRHR desensitization undergoes special attention, considering that the failure of signaling termination during recurrent exposure to stress may be causally linked to pathology [32]. Sex differences in the CRHR1 rate of internalization could explain the increased vulnerability of females to stressrelated disorders [48]. Sex-dependent mechanisms have also been described in CRHR2 and urocortin 1-mediated stress-mediated inflammatory responses [49].

CRHRs are able to form homo- and heteromeric complexes with each other and other GPCRs, such as dopamine1 receptor, displaying different signaling properties than receptors alone [50, 51]. CRH and serotonin system interactions have been described in terms of both molecular and behavioral effects. Enhanced serotonin signaling by $\mathrm{CRH}$ was shown to require $\mathrm{CRH}$-stimulated CRHR1 endocytosis and rapid recycling from endosomes, which resulted in increased cell surface expression of serotonin receptor (5-HT2R), in both HEK293 cells and mouse cortical neurons [52]. 
Heterodimerization between vasopressin receptors and CRHR1 is suggested as a mechanism to explain CRH potentiation by AVP [53]. Oligomerization of CRHR1 and orexin 1 receptor may provide support for functional interactions between $\mathrm{CRH}$ and orexin-A on dopamine release modulation [54].

\section{P2X7R Function in the Brain: Biochemistry and Genetics}

The purinergic ionotropic P2X7R is a member of the P2X family of ATP-gated cation channels that support $\mathrm{K}^{+}$ efflux and $\mathrm{Ca}^{2+} / \mathrm{Na}^{+}$influx [55]. Unlike other family members, P2X7 subunits form homotrimeric complexes [56]. Short stimulation of P2X7R with extracellular ATP, or the more potent agonist 20,30-O-(benzoyl-4-benzoyl)-ATP (BzATP), activates $\mathrm{Ca}^{2+}$ influx. Prolonged or repeated stimulation opens a nonselective cation channel with considerable calcium permeability and induces the formation of a pore permeable to large hydrophilic molecules, eventually leading to cell death $[57,58]$. P2X7R is unique in the $\mathrm{P} 2 \mathrm{X}$ family for the presence of a large cytoplasmic C-terminal tail that is believed to be responsible for the interaction with other proteins and the activation of downstream signaling pathways. P2X7 stimulation in different cellular systems was found to regulate kinases as ERK1/2, JNK1, Akt, and caspases activity (reviewed in [59]).

$\mathrm{P} 2 \mathrm{X} 7 \mathrm{R}$ is predominantly expressed in immune, endothelia, and epithelia cells where it regulates several aspects of immune function [8]. Several brain cell types, including astrocytes, microglia, oligodendrocytes, and Schwan cells express P2X7R [60]. Under basal conditions, P2X7R mRNA expression in neurons was detectable only in glutamatergic neurons of the mouse hippocampus [61].

Microglia, the resident immune cell of the CNS, shares many functions with macrophages such as phagocytosis and proinflammatory cytokines release. Brain injury and psychogenic stimuli increase extracellular ATP, which is sensed by P2X7R in microglia (Fig. 1), leading to NLP3 inflammasome activation resulting in the release of the inflammatory cytokine IL-1 $\beta$ [6]. Thus, P2X7R is a main driver of neuroinflammation, a process involved in neurological diseases, chronic neurodegenerative illnesses, and stress-related psychiatric disorders.

Up to date, 14,369 single nucleotide polymorphisms have been reported for the P2RX7 gene (https://www. ncbi.nlm.nih.gov/snp). The SNP rs2230912 (base change $1405 \mathrm{~A}>\mathrm{G})$, leading to a substitution of glutamine (Gln, Q) by arginine (Arg, R) at codon 460 (Gln460Arg, Q460R), has been identified in individuals with mood disorders [62-64]. Surprisingly, the P2X7R-Q460R variant triggers similar $\mathrm{Ca}^{2+}$ intake, channel currents, and ERK1/2 activation levels compared to the wild-type P2X7R when expressed in HEK293 cells. However, coexpression of the 2 variants - wild-type P2X7R-WT and P2X7R-Q460R dramatically impairs receptor activity. Silencing of either of the coexpressed variants rescues the loss-of-function phenotype. Coimmunoprecipitation and FRET studies proved that P2X7R-Gln460Arg physically interacts with wild-type P2X7R and localizes the trimer to the cell membrane. These findings revealed a novel mechanism of inhibition in which this polymorphism results in a loss of function only when physical interaction occurs between mutated and wild-type subunits [65].

Constitutive P2X7R KO mouse lines have been generated by GlaxoSmithKline, Pfizer, and Lexicon Genetics. However, considering the existence of P2X7 splice variants, the mice from the first 2 companies are not full knockouts [8]. Behavioral tests performed in P2X7 KO mice revealed antidepressants like phenotypes similar to those observed with the Brilliant Blue G P2X7R antagonist in WT animals. Conditional humanized mouse strains were constructed to genetically assess the effect of the amino acid substitution (Gln460Arg, Q460R), associated with mood disorders in humans. These mice that conditionally express human P2X7R in the brain provide a crucial in vivo system for detailed assessment of human P2X7R function, including evaluation of receptor's agonists or antagonists [61]. In line with the in vitro results, coexpression of the human P2X7R-Gln460Arg with the human $\mathrm{P} 2 \mathrm{X} 7 \mathrm{R}-\mathrm{WT}$ in mice resulted in impaired receptor function [66]. Importantly, these mice showed increased stress vulnerability in behavioral tests [66]. Remarkably, they exhibited sleep profile disturbances reminiscent of the altered sleep architecture shown by heterozygous healthy humans. These findings demonstrate that the P2X7RGln460Arg polymorphism confers genetic risk to stressrelated pathologies and suggest that examination of sleep patterns may serve as a relevant diagnostic for mood disorders in patients carrying the rs2230912 SNP [8].

\section{CRH and P2X7R in Brain Areas Implicated in Stress-Related Disorders}

Despite the high prevalence of psychiatric conditions linked to stress, the biological basis of these disorders remains largely unclear. The existence of genetic predisposition, together with environmental factors, are believed
Neuroimmunomodulation 2021;28:52-60 DOI: $10.1159 / 000515130$
Silberstein/Liberman/dos Santos Claro/ Ugo/Deussing/Arzt 
to determine the disease risk. Stressful life events across the lifespan play an important role in the etiology of these diseases [12].

Based on wide evidence that typical antidepressants block the reuptake and metabolism of monoamines such as serotonin and noradrenaline [67], it was proposed that depression originated from disruptions in monoamine neurotransmission. Other studies have reported alterations in the main excitatory and inhibitory neurotransmitters in the brain, glutamate, and GABA [68]. A number of studies have demonstrated that the stress-reactive neuroendocrine system, the HPA axis, and increases in circulating GCs, contribute to the stress-related pathophysiology [12]. These findings led to a focused attention on the CRH system as a key player in stress-related psychiatric disorders [1].

Studies in rodents and in human patients have shown that depressive symptoms are associated with altered neuroplasticity and changes in neurotransmitter levels in the prefrontal cortex and in limbic areas of the brain [69]. In recent years, the hippocampus has received significant attention in mood disorder research, given its key role in stress-related behaviors, sensory processing of multimodal stimuli, learning and memory formation.

Physiological stress induces the release of endogenous hippocampal CRH [70]. Acute activation of hippocampal neurons, as by a rapid release of CRH, contributes to synaptic plasticity and long-term potentiation, mechanisms believed to control learning and memory. Nevertheless, long-lasting $\mathrm{CRH}$ exposure reduces synaptic plasticity and decreases memory which is correlated with morphological changes in neuronal architecture [71].

Site-specific manipulation of $\mathrm{CRH}$ and CRHRs by pharmacological drugs and genetic approaches was carried out to unravel specific roles in brain areas [32]. A mouse line in which CRHR1 function is specifically inactivated in limbic structures exhibited an anxiety-reduced phenotype, showing a direct participation of limbic CRH/ CRHR1 in anxiety-related behavior [72].

The P2X7R is widely expressed in brain regions, such as frontal cortex, hippocampus, amygdala, and striatum [73]. Whether P2X7R is expressed in the CNS only on immunocompetent cells or also in neurons is still controversial. P2X7R distribution has been explored in mice in which a humanized P2RX7 allele can be spatially and temporally controlled by Cre recombinase-mediated inactivation [61]. With this genetic approach, P2X7R mRNA was detected in glutamatergic CA3 neurons of the mouse hippocampus. However, recent work suggested that functional P2X7Rs are absent in neurons of the tri- synaptic network of the rodent hippocampus and that $\mathrm{P} 2 \mathrm{X} 7 \mathrm{R}$ activation in astrocytes releases astrocytic glutamate and GABA nearby CA3 neurons [74]. Astrocyteneuron crosstalk in the hippocampus may protect or aggravate physiological and neuropathological processes.

Alterations in the innate immune system and inflammatory responses have been repeatedly observed in patients with mood disorders, for instance increased concentrations of circulating cytokines such as IL-6, TNF- $\alpha$, and IL-1 $\beta$ [75]. P2X7R is a key regulator of these neurochemical and neuroplastic mechanisms. Stress may be involved in a massive release of ATP-stimulating P2X7Rs, which may favor the release of IL- $1 \beta$. IL- $1 \beta$ has been reported to induce the secretion of $\mathrm{CRH}$ [76] and therefore the release of ACTH and GCs, which together with a number of other inflammatory mediators may lead to psychiatric disorders [77].

Notably, P2X7R has low affinity for ATP $(>100 \mu \mathrm{M})$, requiring atypically high concentrations in order to be activated, which can be released during stress conditions [7]. In fact, acute psychological stress increases the release of ATP from astrocytes, the activation of P2X7R, and the production of IL- $1 \beta$ with the subsequent induction of TNF- $\alpha$ via activation of the NLRP3 inflammasome [75].

\section{Perspectives: CRH System and P2X7R as Therapeutic Targets for Neuropsychiatric Diseases}

The effects of stress on brain structures and function are complex and exhibit a bidirectional pattern depending on duration and intensity of the stimulus. Acute stress enhances synaptic plasticity by a variety of mediators often resulting in a positive development and increased adaptive response. However, chronic stress exposure or intense stimuli are detrimental and believed to be the origin of impaired functions with associated pathophysiological consequences [78].

Psychiatric disorders, behavioral and physiological effect of alcohol withdrawal, relapse to drug in addictions, compulsive eating in obesity, and the onset of neurodegenerative diseases - conditions that involve genetic predisposition and environmental stress - have been linked to the activity of extrahypothalamic brain CRH system [79].

A search for brain barrier penetrant small-molecule compounds to target CRHRs without causing side effects by suppressing the HPA axis is an area of active investigation [4]. Studies in animals and a few studies in humans validated CRHR1 as a target suitable for modulation by antidepressants [12]. However, clinical studies with 
CRHR1 antagonists in depressed subjects gave mixed results so far [3], which might be reflecting the requirement of identifying patients suitable for this treatment and a profound definition of CRH system function to identify molecular targets with therapeutic potential.

On the other hand, animal models of stress-induced disorders have provided convincing evidence of the role of immune components in the brain pathophysiology. P2X7R-mediated neuroinflammatory response is linked to impaired neurotransmission and reduced neuroplasticity, neurobiological processes alterations involved in psychiatric conditions that can be reverted by antidepressant drugs [69]. Importantly, P2X7R gene polymorphisms are associated to depression. In view of that, the P2X7R has been proposed to be a potential target for therapeutic intervention in psychiatric disorders.

In animal models of neurodegenerative diseases, a P2X7R protective role has been described under physiological conditions while a worsening effect was evidenced once the disease was established [75]. Thus, P2X7 may have a beneficial or detrimental role in the nervous system, in the context of neurological pathologies. Would antagonism or agonism of P2X7R activity be the most appropriate strategy? Is there a precise window for therapeutic intervention in P2X7R activity-linked neuroinflammation? These questions highlight the need of a deeper understanding of how P2X7R effects contribute to depressive symptomatology.

Small-molecule antagonists and agonists of P2X7R have been proposed as potential pharmacological treatment of cancer, pain, neurological and neuropsychiatric diseases. Some have shown promising results in animal models but have failed so far in clinical studies [7]. Recently, monoclonal antibodies and nanobodies that mod- ulate the function of human and mouse P2X7R have been developed [80], which may represent new tools for experimental and therapeutic immunomodulation.

Inflammation occurs in a subgroup of approximately $30-50 \%$ of depressed individuals. Understanding the molecular basis and mechanisms of the 2 main systems impacting in the regulation of inflammatory pathways linked to depression - the CRH system and the ATP-gated ion-channel P2X7R - described in this review, are crucial for developing therapies involving control of brain stress responses and immune functions in those patients who potentially would benefit from these particular interventions.

\section{Conflict of Interest Statement}

The authors declare no potential conflict of interests.

\section{Funding Sources}

This work was supported by grants from the Max Planck Society, Germany; NeuroNova gGmbH, Germany; the University of Buenos Aires; CONICET; the Agencia Nacional de Promoción Científica $y$ Tecnológica (ANPCyT), Argentina; and FOCEMMercosur (COF 03/11).

\section{Author Contributions}

S.S. and E.A. designed manuscript content and structure and contributed to writing. A.C.L., P.A.d.S.C., and M.B.U. collaborated with writing, corrections, and art. J.M.D. revised intellectual content. All authors approved the manuscript.

\section{References}

1 de Kloet ER, Joëls M, Holsboer F. Stress and the brain: from adaptation to disease. Nat Rev Neurosci. 2005 Jun;6(6):463-75.

2 Bale TL, Vale WW. CRF and CRF receptors: role in stress responsivity and other behaviors. Annu Rev Pharmacol Toxicol. 2004;44: $525-57$.

3 Paez-Pereda M, Hausch F, Holsboer F. Corticotropin releasing factor receptor antagonists for major depressive disorder. Expert Opin Investig Drugs. 2011 Apr;20(4):519-35.

4 Sanders J, Nemeroff C. The CRF System as a therapeutic target for neuropsychiatric disorders. Trends Pharmacol Sci. 2016 Dec;37(12): 1045-54.
5 Irwin MR, Cole SW. Reciprocal regulation of the neural and innate immune systems. Nat Rev Immunol. 2011 Aug 5;11(9):625-32.

6 Iwata M, Ota KT, Li XY, Sakaue F, Li N, Dutheil S, et al. Psychological stress activates the inflammasome via release of adenosine triphosphate and stimulation of the purinergic type 2X7 receptor. Biol Psychiatry. 2016 Jul 1;80(1):12-22.

7 Bartlett R, Stokes L, Sluyter R. The P2X7 receptor channel: recent developments and the use of P2X7 antagonists in models of disease. Pharmacol Rev. 2014 Jul;66(3):638-75.

8 Deussing JM, Arzt E. P2X7 receptor: a potential therapeutic target for depression? Trends Mol Med. 2018 Sep;24(9):736-47.
9 Petta I, Dejager L, Ballegeer M, Lievens S, Tavernier J, De Bosscher K, et al. The interactome of the glucocorticoid receptor and its influence on the actions of glucocorticoids in combatting inflammatory and infectious diseases. Microbiol Mol Biol Rev. 2016 Jun;80(2):495-522.

10 Cain DW, Cidlowski JA. Immune regulation by glucocorticoids. Nat Rev Immunol. 2017 Apr;17(4):233-47.

11 Liberman AC, Budziñski ML, Sokn C, Gobbini RP, Steininger A, Arzt E. Regulatory and mechanistic actions of glucocorticoids on $\mathrm{T}$ and inflammatory cells. Front Endocrinol. 2018;9:235. 
12 Holsboer F. The rationale for corticotropinreleasing hormone receptor (CRH-R) antagonists to treat depression and anxiety. J Psychiatr Res. 1999 May-Jun;33(3):181-214.

13 Menke A. Is the HPA axis as target for depression outdated, or is there a new hope? Front Psychiatry. 2019;10:101.

14 Miller AH, Raison CL. The role of inflammation in depression: from evolutionary imperative to modern treatment target. Nat Rev Immunol. 2016 Jan;16(1):22-34.

15 Liberman AC, Trias E, da Silva Chagas L, Trindade P, Dos Santos Pereira M, Refojo D, et al. Neuroimmune and inflammatory signals in complex disorders of the central nervous system. Neuroimmunomodulation. 2018;25(5-6):246-70.

16 Binder EB, Salyakina D, Lichtner P, Wochnik GM, Ising M, Pütz B, et al. Polymorphisms in FKBP5 are associated with increased recurrence of depressive episodes and rapid response to antidepressant treatment. Nat Genet. 2004 Dec;36(12):1319-25.

17 Klengel T, Mehta D, Anacker C, Rex-Haffner M, Pruessner JC, Pariante CM, et al. Allelespecific FKBP5 DNA demethylation mediates gene-childhood trauma interactions. Nat Neurosci. 2013 Jan;16(1):33-41.

18 Scharf SH, Liebl C, Binder EB, Schmidt MV, Müller MB. Expression and regulation of the Fkbp5 gene in the adult mouse brain. PLoS One. 2011 Feb 9;6(2):e16883.

19 Antunica-Noguerol M, Budziñski ML, Druker J, Gassen NC, Sokn MC, Senin S, et al. The activity of the glucocorticoid receptor is regulated by SUMO conjugation to FKBP51. Cell Death Differ. 2016 Oct;23(10):1579-91.

20 Daneri-Becerra C, Zgajnar NR, Lotufo CM, Ramos Hryb AB, Piwien-Pilipuk G, Galigniana MD. Regulation of FKBP51 and FKBP52 functions by post-translational modifications. Biochem Soc Trans. 2019 Dec 20;47(6): 1815-31.

21 Liberman AC, Budziñski ML, Sokn C, Gobbini RP, Ugo MB, Arzt E. SUMO conjugation as regulator of the glucocorticoid receptorFKBP51 cellular response to stress. Steroids. 2020 Jan; 153:108520.

22 Hartmann J, Wagner KV, Liebl C, Scharf SH, Wang XD, Wolf M, et al. The involvement of FK506-binding protein 51 (FKBP5) in the behavioral and neuroendocrine effects of chronic social defeat stress. Neuropharmacology. 2012 Jan;62(1):332-9.

23 Bouwmeester T, Bauch A, Ruffner H, Angrand PO, Bergamini G, Croughton $\mathrm{K}$, et al. A physical and functional map of the human TNF-alpha/NF-kappa B signal transduction pathway. Nat Cell Biol. 2004 Feb;6(2):97-105.

24 Erlejman AG, De Leo SA, Mazaira GI, Molinar AM, Camisay MF, Fontana V, et al. NF- $\kappa B$ transcriptional activity is modulated by FK506binding proteins FKBP51 and FKBP52: a role for peptidyl-prolyl isomerase activity. J Biol Chem. 2014 Sep 19;289(38):26263-76.
25 Valbuena Perez JV, Linnenberger R, Dembek A, Bruscoli S, Riccardi C, Schulz MH, et al. Altered glucocorticoid metabolism represents a feature of macroph-aging. Aging Cell. 2020 Jun;19(6):e13156.

26 Britton DR, Koob GF, Rivier J, Vale W. Intraventricular corticotropin-releasing factor enhances behavioral effects of novelty. Life Sci. 1982 Jul 26;31(4):363-7.

27 Sutton RE, Koob GF, Le Moal M, Rivier J, Vale W. Corticotropin releasing factor produces behavioural activation in rats. Nature. 1982 May 27;297(5864):331-3.

28 Eaves M, Thatcher-Britton K, Rivier J, Vale W, Koob GF. Effects of corticotropin releasing factor on locomotor activity in hypophysectomized rats. Peptides. 1985 Sep-Oct;6(5):923-6.

29 van Gaalen MM, Stenzel-Poore MP, Holsboer F, Steckler T. Effects of transgenic overproduction of $\mathrm{CRH}$ on anxiety-like behaviour. Eur J Neurosci. 2002 Jun;15(12):2007-15.

30 Griebel G, Holsboer F. Neuropeptide receptor ligands as drugs for psychiatric diseases: the end of the beginning? Nat Rev Drug Discov. 2012 May 18;11(6):462-78.

31 Timpl P, Spanagel R, Sillaber I, Kresse A, Reul JM, Stalla GK, et al. Impaired stress response and reduced anxiety in mice lacking a functional corticotropin-releasing hormone receptor 1. Nat Genet. 1998 Jun;19(2):162-6.

32 Henckens MJ, Deussing JM, Chen A. Regionspecific roles of the corticotropin-releasing factor-urocortin system in stress. Nat Rev Neurosci. 2016 Oct;17(10):636-51.

33 Gallagher JP, Orozco-Cabal LF, Liu J, Shinnick-Gallagher P. Synaptic physiology of central CRH system. Eur J Pharmacol. 2008 Apr 7;583(2-3):215-25.

34 Refojo D, Schweizer M, Kuehne C, Ehrenberg S, Thoeringer C, Vogl AM, et al. Glutamatergic and dopaminergic neurons mediate anxiogenic and anxiolytic effects of CRHR1. Science. 2011 Sep 30;333(6051):1903-7.

35 Dedic N, Kühne C, Jakovcevski M, Hartmann J, Genewsky AJ, Gomes KS, et al. Chronic $\mathrm{CRH}$ depletion from GABAergic, long-range projection neurons in the extended amygdala reduces dopamine release and increases anxiety. Nat Neurosci. 2018 Jun;21(6):803-7.

36 Klengel T, Binder EB. Epigenetics of stressrelated psychiatric disorders and gene $\times$ environment interactions. Neuron. 2015 Jun 17; 86(6): 1343-57.

37 Inda C, Armando NG, Dos Santos Claro PA, Silberstein S. Endocrinology and the brain: corticotropin-releasing hormone signaling. Endocr Connect. 2017 Aug;6(6):R99-R120.

38 Deussing JM, Chen A. The corticotropin-releasing factor family: physiology of the stress response. Physiol Rev. 2018 Oct 1;98(4): 2225-86.

39 Kovalovsky D, Refojo D, Liberman AC, Hochbaum D, Pereda MP, Coso OA, et al. Activation and induction of NUR77/NURR1 in corticotrophs by CRH/cAMP: involvement of calcium, protein kinase A, and MAPK pathways. Mol Endocrinol. 2002 Jul;16(7):1638-51.
40 Markovic D, Punn A, Lehnert H, Grammatopoulos DK. Molecular determinants and feedback circuits regulating type $2 \mathrm{CRH}$ receptor signal integration. Biochim Biophys Acta. 2011 May;1813(5):896-907.

41 Bonfiglio JJ, Inda C, Senin S, Maccarrone G, Refojo D, Giacomini D, et al. B-Raf and CRHR1 internalization mediate biphasic ERK1/2 activation by CRH in hippocampal HT22 Cells. Mol Endocrinol. 2013 Mar;27(3): 491-510.

42 Inda C, Dos Santos Claro PA, Bonfiglio JJ, Senin SA, Maccarrone G, Turck CW, et al. Different cAMP sources are critically involved in $\mathrm{G}$ protein-coupled receptor CRHR1 signaling. J Cell Biol. 2016 Jul 18;214(2):18195.

43 Inda C, Bonfiglio JJ, Dos Santos Claro PA, Senin SA, Armando NG, Deussing JM, et al. cAMP-dependent cell differentiation triggered by activated CRHR1 in hippocampal neuronal cells. Sci Rep. 2017 May 16;7(1): 1944.

44 Bonfiglio JJ, Inda C, Refojo D, Holsboer F, Arzt E, Silberstein S. The corticotropin-releasing hormone network and the hypothalamic-pituitary-adrenal axis: molecular and cellular mechanisms involved. Neuroendocrinology. 2011;94(1):12-20.

45 Van Kolen K, Dautzenberg FM, Verstraeten K, Royaux I, De Hoogt R, Gutknecht E, et al. Corticotropin releasing factor-induced ERK phosphorylation in AtT20 cells occurs via a cAMP-dependent mechanism requiring EPAC2. Neuropharmacology. 2010 Jan;58(1): $135-44$.

46 Refojo D, Echenique C, Müller MB, Reul JM, Deussing JM, Wurst W, et al. Corticotropinreleasing hormone activates ERK1/2 MAPK in specific brain areas. Proc Natl Acad Sci USA. 2005 Apr 26;102(17):6183-8.

47 Dos Santos Claro PA, Inda C, Armando NG, Piazza VG, Attorresi A, Silberstein S. Assessing real-time signaling and agonist-induced CRHR1 internalization by optical methods. Methods Cell Biol. 2019;149:239-57.

48 Valentino RJ, Van Bockstaele E, Bangasser D. Sex-specific cell signaling: the corticotropinreleasing factor receptor model. Trends Pharmacol Sci. 2013 Aug;34(8):437-44.

49 Hasdemir B, Mhaske P, Paruthiyil S, Garnett EA, Heyman MB, Matloubian M, et al. Sexand corticotropin-releasing factor receptor 2 dependent actions of urocortin 1 during inflammation. Am J Physiol Regul Integr Comp Physiol. 2016 Jun 1;310(11):R1244-57.

50 Schulein R, Gibert A, Rutz C. Functional significance of the signal peptides of corticotropin-releasing factor receptors. Curr Mol Pharmacol. 2017;10(4):311-7.

51 Yarur HE, Andrés ME, Gysling K. Type $2 \beta$ corticotrophin releasing factor receptor forms a heteromeric complex with dopamine D1 receptor in living cells. Front Pharmacol. 2019;10:1501. 
52 Magalhaes AC, Holmes KD, Dale LB, CompsAgrar L, Lee D, Yadav PN, et al. CRF receptor 1 regulates anxiety behavior via sensitization of 5-HT2 receptor signaling. Nat Neurosci. 2010 May;13(5):622-9.

53 Murat B, Devost D, Andrés M, Mion J, Boulay V, Corbani M, et al. V1b and CRHR1 receptor heterodimerization mediates synergistic biological actions of vasopressin and CRH. Mol Endocrinol. 2012 Mar;26(3):502-20.

54 Navarro G, Quiroz C, Moreno-Delgado D, Sierakowiak A, McDowell K, Moreno E, et al. Orexin-corticotropin-releasing factor receptor heteromers in the ventral tegmental area as targets for cocaine. J Neurosci. 2015 Apr 29; 35(17):6639-53.

55 Khakh BS, North RA. P2X receptors as cellsurface ATP sensors in health and disease. Nature. 2006 Aug 3;442(7102):527-32.

56 Nicke A. Homotrimeric complexes are the dominant assembly state of native $\mathrm{P} 2 \mathrm{X} 7$ subunits. Biochem Biophys Res Commun. 2008 Dec 19;377(3):803-8.

57 Surprenant A, Rassendren F, Kawashima E, North RA, Buell G. The cytolytic P2Z receptor for extracellular ATP identified as a P2X receptor (P2X7). Science. 1996 May 3; 272(5262):735-8.

58 Virginio C, MacKenzie A, North RA, Surprenant A. Kinetics of cell lysis, dye uptake and permeability changes in cells expressing the rat P2X7 receptor. J Physiol (Lond). 1999 Sep 1;519 Pt 2(Pt 2):335-46.

59 Kopp R, Krautloher A, Ramírez-Fernández A, Nicke A. P2X7 interactions and signaling making head or tail of it. Front Mol Neurosci. 2019;12:183.

60 Miras-Portugal MT, Sebastián-Serrano Á, de Diego García L, Díaz-Hernández M. Neuronal P2X7 receptor: involvement in neuronal physiology and pathology. J Neurosci. 2017 Jul 26;37(30):7063-72.

61 Metzger MW, Walser SM, Aprile-Garcia F, Dedic N, Chen A, Holsboer F, et al. Genetically dissecting P2rx7 expression within the central nervous system using conditional humanized mice. Purinergic Signal. 2017 Jun; 13(2):153-70.
62 Lucae S, Salyakina D, Barden N, Harvey M, Gagné B, Labbé M, et al. P2RX7, a gene coding for a purinergic ligand-gated ion channel, is associated with major depressive disorder. Hum Mol Genet. 2006 Aug 15;15(16):243845.

63 Hejjas K, Szekely A, Domotor E, Halmai Z, Balogh G, Schilling B, et al. Association between depression and the Gln460Arg polymorphism of P2RX7 gene: a dimensional approach. Am J Med Genet B Neuropsychiatr Genet. 2009 Mar 5;150b(2):295-9.

64 Soronen P, Mantere O, Melartin T, Suominen K, Vuorilehto M, Rytsälä H, et al. P2RX7 gene is associated consistently with mood disorders and predicts clinical outcome in three clinical cohorts. Am J Med Genet B Neuropsychiatr Genet. 2011 Jun;156b(4): 435-47.

65 Aprile-Garcia F, Metzger MW, Paez-Pereda $\mathrm{M}$, Stadler H, Acuña M, Liberman AC, et al. Co-expression of wild-type P2X7R with Gln460Arg variant alters receptor function. PLoS One. 2016;11(3):e0151862.

66 Metzger MW, Walser SM, Dedic N, AprileGarcia F, Jakubcakova V, Adamczyk M, et al. Heterozygosity for the mood disorder-associated variant Gln460Arg alters P2X7 receptor function and sleep quality. J Neurosci. 2017 Nov 29;37(48):11688-700.

67 Lopez-Munoz F, Alamo C. Monoaminergic neurotransmission: the history of the discovery of antidepressants from 1950s until today. Curr Pharm Des. 2009;15(14):1563-86.

68 Wohleb ES, Gerhard D, Thomas A, Duman RS. Molecular and cellular mechanisms of rapid-acting antidepressants ketamine and scopolamine. Curr Neuropharmacol. 2017; 15(1):11-20.

69 Wohleb ES, Franklin T, Iwata M, Duman RS Integrating neuroimmune systems in the neurobiology of depression. Nat Rev Neurosci. 2016 Aug;17(8):497-511.

70 Chen Y, Brunson KL, Adelmann G, Bender RA, Frotscher M, Baram TZ. Hippocampal corticotropin releasing hormone: pre- and postsynaptic location and release by stress. Neuroscience. 2004;126(3):533-40.
71 Maras PM, Baram TZ. Sculpting the hippocampus from within: stress, spines, and $\mathrm{CRH}$. Trends Neurosci. 2012 May;35(5):315-24.

72 Müller MB, Zimmermann S, Sillaber I, Hagemeyer TP, Deussing JM, Timpl P, et al. Limbic corticotropin-releasing hormone receptor 1 mediates anxiety-related behavior and hormonal adaptation to stress. Nat Neurosci. 2003 Oct;6(10):1100-7.

73 Andrejew R, Oliveira-Giacomelli Á, Ribeiro DE, Glaser T, Arnaud-Sampaio VF, Lameu C, et al. The P2X7 receptor: central hub of brain diseases. Front Mol Neurosci. 2020;13:124.

74 Khan MT, Deussing J, Tang Y, Illes P. Astrocytic rather than neuronal $\mathrm{P} 2 \mathrm{X} 7$ receptors modulate the function of the tri-synaptic network in the rodent hippocampus. Brain Res Bull. 2019 Sep;151:164-73.

75 Kanellopoulos JM, Delarasse C. Pleiotropic roles of P2X7 in the central nervous system. Front Cell Neurosci. 2019;13:401.

76 Barbanel G, Ixart G, Szafarczyk A, Malaval F, Assenmacher I. Intrahypothalamic infusion of interleukin-1 beta increases the release of corticotropin-releasing hormone (CRH 41) and adrenocorticotropic hormone (ACTH) in free-moving rats bearing a push-pull cannula in the median eminence. Brain Res. 1990 May 14;516(1):31-6.

77 Illes P, Verkhratsky A, Tang Y. Pathological ATPergic signaling in major depression and bipolar disorder. Front Mol Neurosci. 2019; $12: 331$.

78 Joels M, Baram TZ. The neuro-symphony of stress. Nat Rev Neurosci. 2009 Jun;10(6):45966.

79 Zorrilla EP, Logrip ML, Koob GF. Corticotropin releasing factor: a key role in the neurobiology of addiction. Front Neuroendocrinol. 2014 Apr;35(2):234-44.

80 Koch-Nolte F, Eichhoff A, Pinto-Espinoza C Schwarz N, Schäfer T, Menzel S, et al. Novel biologics targeting the P2X7 ion channel Curr Opin Pharmacol. 2019 Aug;47:110-8. 